\title{
Software Patents And The Internet: Lessons From The Compuserve/Unisys Graphics Interchange Format Case Study.
}

\author{
Jenny Shearer \\ (HyperMedia Unit, University of Auckland, New Zealand \\ jshearer@cs.auckland.ac.nz) \\ Arnould Vermeer \\ (Practical ComputerScience 1, University of Hagen, Germany)
}

\begin{abstract}
The attempt by Unisys to obtain royalties from the Lempel Zev Welch Graphics Interchange Format specification through Compuserve has wide implications for the Internet. Increased activity in the US software patents area is likely to result in damage to progress of the software arts and the Internet, and to generate upscaled protest from Internet users. The LZW GIF case highlights the Internet culture in favour of free and unfettered development. Clarification of this important principle will have a major effect on the future of the Internet.
\end{abstract}

Key Words: Software patents, debate, Internet, Compuserve, Unisys, LZW GIF.

Categories: K.O, K.4.1, K.5.1, K.5.2, K.6.3

\section{Introduction}

A developing international problem with software patents has been illustrated by the recent Compuserve/Unisys GIF debate on the Internet. A conflict between legal collectors of royalties and makers/ users of software, has signs of escalating in the immediate future. The battle lines are already being drawn. While the United States legislature is preparing to pass laws ensuring patents licences last 20 years, in line with GATT resolutions, members of the Internet community are campaigning on the grounds that software patents are unnecessary, and will damage the Internet and progress in the software arts generally.

In the US, software patents are criticised, but there appears to be little political will to curb them. The well-publicised speech of US Vice-President Al Gore last year on the information superhighway stated a commitment to protection of intellectual property rights. To challenge large and powerful corporations on an issue involving considerable legal complexity is a risky political undertaking. However ACIS (American Committee For Interoperable Systems), which represents large IT companies, has suggested procedural reforms are necessary in the software patents area, and that these reforms should proceed whether or not a process of global harmonisation goes ahead.(1)

Critics of US software patent laws say inventors of software are already protected by copyright and trade secret law, and inappropriate patents are approved, eg "obvious" applications, which may already be well known by programmers or which may be reinvented over and over in the normal course of software development. They claim software developments, whether patented or not, build on prior art, and thus patents are inappropriate. Central to the debate, however, is the charge that large companies are viewing patents as an opportunity to profiteer at the expense of the international software development community.

The wider implications of this perceived threat are important. The proliferation of software patents in the United States may in short order create a heavy international impact, on small businesses and community organisations seeking software to develop their operation.The running of, say, hospitals and 
schools could be affected in countries inside and outside the US, because of the actions of US patents lawyers. Progress in developing new networks and extending functions of the Internet would also be affected by the cost of extended patents searches and payment of royalties. The international community, as well as factions of the industry in the United States, may move to express their dissatisfaction with protest through the Internet, the primary mode of communication for the computer industry. With little organised political process developed in the Internet, allegations of profiteering and unethical conduct may be freely aired, but the outcome is likely to be messy. Organised large-scale political protest is still some time away.

The Compuserve/Unisys GIF case has underlined a founding principle widely accepted in the Internet, that development should be unfettered and free. But apart from demonstrating an increased politicisation of Internet users, the case has stimulated a lengthy on-line discussion on the software patents issue.

The Compuserve case included a rebellion by customers and Internet users who, acting as individuals, denied royalties should be paid for use of the LZW patent. Compuserve was "flamed" on Internet newsgroups when the decision to pay was announced. Later, a significant objection by users was the perceived time lag of some years between the filing of the patent, and the demand by Unisys that the royalties be paid. In the interim, Compuserve had incorporated the LZW patent into its development programme. The widespread use of the patent appeared to provide a substantial profit opportunity for Unisys. Unisys has denied there was a motive towards large profits, and says it was defending its patent, once its use was discovered, on the principle of protecting the interests of shareholders who have invested in technology development.(2)

Compuserve responded to the criticism by announcing the development of a new GIF standard.

\section{Case Study}

Compuserve Communications is a company running a large commercial computer communications network in the US. In 1987, CompuServe designed the Graphics Interchange Format (GIF) specification for graphics files. The GIF specification incorporated the Lempel Zev Welch (LZW) compression technology. In early 1993, Unisys Corporation notified Compuserve of patents rights granted to LZW.The patent covers methods and apparatus for lossless compression and decompression of digital data. Unisys holds a U.S patent (number $4,558,302$ ) as well as equivalent patents on the technology in Canada, France, Germany, U.K. and Italy. Equivalent patents are also pending in Japan. Compuserve reached a licensing agreement with Unisys in mid 1994, and on December 29, 1994, announced the GIF Developer Agreement. The agreement meant developers of software and shareware using the LZW technology, intended for use in conjunction with Compuserve, were liable to pay royalties of 1.5 percent.

The result of this attempt to enforce a software patent after the technology had been widely used for some years, caused an outcry from customers and sections of the Internet.

In defending its actions online, Compuserve said when it took up the LZW algorithm, the company had believed it to be in the public domain. In 1993, Unisys had informed Compuserve that it had a patent on the LZW algorithm "that it would enforce". (3) The company assured the community it would not profit from the licensing agreement, and suggested that developers might negotiate independently with Unisys, choose other specifications that did not incorporate LZW, or seek independent counsel on the merit of the Unisys patent claim.

Compuserve then announced it would offer its resources to "develop a follow-on specification to GIF that will offer significant enhancements and be free and open." (4) In an apparent major exercise in damage control, the company solicited input from GIF users such as commercial graphics vendors, the CompuServe Go Graphics Forum community, Internet communities including the World Wide Web, and bulletin board developers and users. In retrospect, Compuserve believes the row showed the effectiveness of computer-based communications in allowing customers' input, with a resulting 
improvement to services. Spokesperson Pierce Reid (5) said the company chose to ignore "misinformation" and negative comment after the GIF royalties decision was announced.

"Someone compared it to the attack on Pearl Harbour." ( the Japanese surprise bombing of US warships, which effectively brought the US into World War II )

"In some ways, you need to have a thick skin, but there is the issue of the greater good, that there are people who can come together. The public brainstorming sessions are of value."

Reid says the row took the issue of a better GIF specification (GIF 24, using a png algorithm) "off the back burner". The outcome is an improved specification which will be copyrighted. However the company plans to have it administered by a third party in order to guarantee it is freely available to the public.

Reid says it is logical to look towards online services such as the Internet undergoing a process of increasing regulation. Whether this would be acceptable would be dependent on whether freedom of discussion was maintained.

"On the other hand, it would make people responsible for such actions as saying "fire" in a crowded theatre."

\section{Discussion}

The GIF case is an indicator of how software patents are destined to be a growth industry in the United States. For US lawyers and patents examiners, it is simply a matter of extending the realm of existing law into an area which for 20 or so years has seen little patents filing activity. Software engineer Gregory Aharonian warned in the January 1993 issue of "Communications of the ACM (Association for Computing Machinery)" that large numbers of software patents were being wrongly awarded by the US Patents and Trademark Office, and that he foresaw the number of software patents would grow even faster, "despite public comments and any current congressional activities." (6)

Aharonian, who runs an Internet Patent News Service, has calculated the 1995 software patents total will be around 5,400, on the basis of an average of 103 patents awarded a week in the first 16 weeks of 1995. The 1994 total was 4,500 software patents. (7)

\subsection{What Is Patentable?}

Criticism of the system, of which inconsistency is a major feature, may be made from examination of some of the existing patents. IBM, for example, placed UNIX in the public domain when royalties seemed too difficult to collect (8) However IBM has been active in placing other patents, some of which appear obvious.

Patent number 4,622, 641, filed in 1983, assignee IBM, is described (9) as a "user friendly procedure for the generation and display of geometric figures on a graphics screen (which) uses a cursor placement device such as a joystick to both define the initial position and size of the geometrical figure. Two specific examples are described: the generation of a circle and the generations of a square or rectangle. In the first example, the cursor is first positioned to point to the centre of the circle at which point a small circle is drawn. The circle is expanded in response to the pressing of a designated key by the user until the desired size is attained. In the second example, the pointing by the cursor is to the upper left corner of the square or rectangle., and the square or rectangle is then expanded in response to the user deflecting the joy stick down and to the right.'

Patent number 4,648.062, filed in 1985, assignee IBM, is described as a method for providing an online help facility for interactive information handling systems. Comment (10) from the MIT files on the patent: 
“A pop-up window decribes valid choices for user unput.”

Patent number 4, 687, 353, filed in 1986, assignee IBM, is described (11) as follows:

"The patent appears to be on printing a document with different indentation than it is stored with; a suggested implementation is tabbing from from the left margin before beginning to print each line."

\subsection{Reactions of the Internet Community}

A commentator on a Usenet newsgroup has criticised obvious or "nonsense" patents applications.

"These patents are a weapon (used) by large companies against small ones, a weapon that will grow in time if software patents become widely accepted." (12)

Another Usenet newsgroup commentator claims small companies do not benefit from patents laws:

"We don't need patents to protect Littleguy, Inc. from big companies, such as Microsoft. If it makes more sense for Microsoft to purchase Littleguy's technology than develop it themselves, they'll do so whether it is patented or not. My experience as an in-house lawyer at Computer Associates (CA) which is the second largest software company in the world and an aggressive acquirer of companies, supports this view. CA does not believe in patents. They don't use them to protect their products and don't put much value in them in evaluating potential acquisition candidates. Of the 50 plus acquisitions I completed for CA, none of them had any patented technology to speak of. CA is also living proof that software companies don't need patents to make tons of money ('94 revenues were well over $\$ 2$ billion).(13)

Software developers are expressing concern about software patents and copyright issues, in ongoing discussions of specialist Usenet newsgroups such as gnu.misc.discuss and comp.software eng. And in 1993, a number of prominent members of the ACM spoke out against a new ACM Code of Ethics which they thought may be read as being incompatible with political activity against patents or extended copyrights.(14)

Clause 1.5 of the Code included an undertaking to "honour property rights including copyrights and patents."

In their statement printed in "Communications of the ACM" the writers commented:

"Surveys suggest that most members disapprove of having patents in software at all; yet the moral imperative calls on members to honour what they may regard as a disaster for their field."

In response, Chair of the ACM Code of Ethics revising committee, Ronald Anderson, defended the code, but encouraged debate on the issues.

"Certainly, most ACM members would like improvement in the socio-technical-legal system to protect intellectual products while promoting exchange of ideas and professional progress. Such improvements require "political advocacy" and legislation." (15)

A spokesperson for Adobe Systems Incorporated, a major company involved in electronic publishing, commented to a public hearing held by the US Commerce Department last year that the constitutional mandate to promote progress in the useful arts is not served by the issuance of patents on software. (16)

"Revenues are being sunk into legal costs instead of into research and development..."

"The case Information International, Inc.v. Adobe, et. al. was filed five years ago. Last year, the trial court ordered for Adobe, finding no infringement. In December, the Appeals Court for the Federal Circuit unanimously affirmed that judgement. Yet, in that time, it has cost Adobe over $\$ 4.5$ million in legal fees and expenses. I (Douglas Brotz, a scientist) have spent over 3,000 hours of my time and at least another thousand hours was spent by others at Adobe. Our Chairman of the Board spent a month at the trial. This type of company behaviour would not be high on anyone's list of ways to promote progress." (17)

A recent decision by the US Court of Appeals shows how litigation over software issues is now threatening to muddy the waters of copyright law. Lotus Development Corporation has been unsuccessful in its effort to sue Borland International Inc. for creating a Quattro programme which 
included use of a virtually identical copy of the Lotus 1-2-3 menu tree. (18) Borland did not copy any of Lotus's underlying computer code; it copied only the words and structure of Lotus's menu command hierarchy.The Court of Appeals in March overturned a decision in favour of Lotus made by the District Court. The Court of Appeals found the menu commands are an uncopyrightable "method of operation."

In a"Concurrence" (19) on the Judgement, Circuit Judge Boudin (one of the presiding judges) said:

"Requests for the protection of computer menus present the concern with fencing off access to the commons in an acute form. A new menu may be a creative work, but over time its importance may come to reside more in the investment that has been made by users in learning the menu and in building their own mini-programs-macros- in reliance apon the menu. Better typewriter keyboard layouts may exist, but the familiar QUERTY keyboard dominates the markets because that is what everybody has learned to use...

"Thus, to assume that computer programs are just one more new means of expression, like a filmed play, may be quite wrong... Applying copyright law to computer programs is like assembling a jigsaw puzzle whose pieces do not quite fit."

The problems presented by such cases are numerous. For companies which will bring copyright actions on such grounds as a command menu using terms like "copy" and "print," the field is wide open. With no clear direction from the US Congress on the limits of patent and copyright law as related to software patents, future lawsuits may be expected to be numerous, and the mid-range outcome, at least, alarming to those occupying the "commons" of the Internet.

Building up case law in this area is an unsatisfactory response to the difficulties of US middle-ranked software companies, and will have major international repercussions. The difficulties facing companies in the US is highlighted by the European environment, in which software patents have not been allowed. However, with the acceptance of the GATT package (20) by European countries, litigation and unproductive stalking of software developers over patents and copyright appear inevitable. The largest US companies are protecting themselves with cross-licensing deals, as predicted by the League For Programming Freedom. (LPF) (21) It is unlikely the issue would be taken up substantively by the Internet Society, which concerns itself with governance, rather than political issues. Pressure groups such as the Electronic Frontier Foundation (EFF) are vocal on the issue of freedom of the Internet, but have not settled on a basis for inclusive Internet-wide political process.

The LPF, an organisation opposed to the existence of software patents, has undertaken a campaign to inform the Internet community on the issue, and provides information to assist companies in formulating public policies against patents.

"The clearest way out of the current situation involves companies opposed to software patents formulating and adopting public policies that oppose their continued issuance."(22)

The Compuserve/Unisys GIF case shows that though the Internet has no official political centre, people using it have a certain cultural outlook which enables them to take political action by the accumulated effect of individual (and voluable) protest. This effect of public opinion in the Internet is not moderated by the usual protocols of media representations, protests to government representatives, and so on, operating within the framework of defamation law and standard public procedure.

Rather, the Internet environment is inhabited by a community with a particular loyalty to the Internet environment, who are committed to the principle of freedom and open use of technology relating to the Internet.

Companies (such as Compuserve) attempting to work in this volatile environment must on the one hand, obey the law, while also pleasing the customers, who may have a different, but not stated, agenda. The problems faced by Compuserve were to behave as a company obedient to the law, and to pass on costs incurred by software royalties, while also fielding an angry backlash from customers who said they were not prepared to pay. This backlash included comments which may have proved 
damaging to the company's standing in the Internet community, with the possibility of accompanying financial repercussions. While in this case Compuserve was able to drop the patented GIF format in response to client dissatisfaction, in other cases the dilemma might prove financially injurious to a company caught in a similar patents dispute.

It may be time for the Internet "community", ( the cultural entity discussed in widely read books such as "The Virtual Community" by Howard Rheingold), (23) to reassess itself in terms of its behaviour as a political sector. Though its philosophy works against development of an organised political system, it may be perceived that "kneejerk" mass responses by users to circumstances they see as unfair, may perpetrate further injustice.

On the other hand, to have political activity which is not formalised may be an advantage. The Compuserve/Unisys GIF case shows that the threat of customer boycott drew an immediate response from Compuserve. Given the unique decentralised nature of the Internet, and the intelligent strata of people using it, it might be possible to threaten to conduct, or to actually conduct, boycotts against companies inflicting patents actions seen as damaging by the Internet community. If these events occurred with minimal orchestration, the lawyers could find themselves in the unusual position of having no-one to sue. Given that it is possible to present the community with correct information and full discussion, eg through newsgroups and sites of political pressure groups, political action could be dictated by individual response to violations of principles held by the majority, rather than by traditional policy creation methods.

\section{Conclusion}

The dispute shows a number of matters remain unresolved. That is, the baseline question of patents royalties and a software using population unwilling to pay them. Unisys, under the GIF LZW license terms, does not require license fees for non-commercial or not-for-profit applications. Presumably, in the future, Unisys or any other company could choose not to make such community-minded decisions. The decision by Unisys to charge royalties indicates that a claim is being staked on the territory. It is unlikely, given the motivation of commercial corporations to make profits, that such claims will be voluntarily withdrawn.

A set of stated ethical principles may work some way towards moderating debates such as the Unisys/Compuserve GIF row. It might also provide a framework for political activity protective of the Internet. For example, if it is accepted that Internet users wish to encourage the best technology towards development of the Internet and global information systems generally, then the argument by large corporations that they have a right to make profits from software patents, (which may incidentally damage development), is seen as a claim with less merit.

Presumably, it would then be the aim of Internet users to facilitate a global harmonisation scheme which would protect intellectual property rights, but not past the point where such rights hinder development of the software arts.

Internet users, who have shown they are not taking their freedom for granted, may need to look towards developing active political pathways to establish and defend their point of view on political issues of major importance, such as the software patents issues. The traditional political process, taking place on a national basis or through international forums, may not serve the interests of Internet users, or the best interests of the progress of information technology.

\section{References}

1. [ Byrne, C 1994] ACIS (American Committee for Interoperable Systems) submission to a public hearing by the Patent and Trademark Office, US Department of Commerce. <http://www.uspto.gov/text/pto/hearings/remarks/text>

(February 1995) 
2. [ Unisys Corporation 1995] LZW Patent Frequently Asked Questions. <http:// www.unisys.com/Lead Story/lzw terms.html>

(February 1995)

3. [Oren,T 1995] "Key Points on Unisys/Compuserve Licensing Agreement."

On-line announcement from Compuserve Communications,

( Compuserve communications,January 1995)

4. [Oren, T 1995] On-line announcement on GIF issue from Compuserve

Communications. (Compuserve Communications, January, 1995)

5. [ Reid, P 1995] Compuserve Communications spokesperson, personal communication. (March 3,1995).

6. [ Aharonian, G 1993] Forum. Setting the Record Straight on Patents. Communications of the ACM. January 1993, Volume 36, Number 1. pp.17-18. (ACM 1515 Broadway, New York)

7. [Aharonian, G. 1995] Software Patenting Chaos Continues. (Internet Patent News Service. patents@world.std.com )

8. [McIlroy,D.1995] Partial List of Software Patents. Comment. (ftp mintaka.lcs.mit.edu:/mitlpf/ai/patent-list.)

9. [1995] Partial List of Software Patents.

(ftp.mintaka.lcs.mit.edu:/mitlpf/ai/patent-list.)

10. [1995] Partial List of Software Patents.

(ftp.mintaka.lcs.mit.edu:/mitlpf/ai/patent-list.)

11. [1995] Partial List of Software Patents. (ftp. mintaka lcs.mit.edu:/mitlpf/ai/patent-list)

12. [Eggert, P 1995] "Why Software Patents Cannot Work" (Usenet newsgroup misc.int.property, February 1995)

13. [Gracin, H 1995] "Software Patents". ( Usenet newsgroup misc.int. property, February 1995)

14. [ Steele, Jr. GL. Hillis, D. Stallman, R. Sussman GJ. Minsky, M. McCarthy, J. Backus, J. Corbato, FJ. 1993]

Forum . Code of Ethics Reconsidered.

Communications of the ACM. July 1993 Volume 36, Number 7, pg 17.

(ACM 1515 Broadway, New York)

15. [ Anderson, RE 1993] Forum. Response to Code of Ethics Reconsidered. Communications of the ACM July 1993 Volume 36, Number 7 pg 17. (ACM 1515 Broadway, New York)

16. [ Brotz, D 1994] Submission on behalf of Adobe Systems Incorporated, to a public hearing by the Patent and Trademark Office, US Department of Commerce.

(http://www.uspto.gov/text/pto/hearings/remarks/text)

(January, 1994.)

17. [ Brotz, D 1994] Submission on behalf of Adobe Systems Incorporated, to a public hearing by the Patent and Trademark Office, US Department of Commerce. (http://www.uspto.gov/text/pto/hearings/remarks/text) (January, 1994)

18. [ Lotus Dev. Corp. v.Borland Intl., Inc. 1995] Lotus Development Corporation, Plaintiff, Appellee, v. Borland International, Inc., Defendant, Appellant. No. 93-2214.

(United States Court of Appeals for the First Circuit US App. LEXIS 4618 March 9, 1995, Decided) 
19. [ Cicuit Judge Boudin, 1995] Lotus Development Corporation, Plaintiff, Appellee, v. Borland International, Inc.,

Defendant, Appellant. No. 932214.

(United States Court of Appeals for the First Circuit US App. LEXIS 4618 March 9, 1995, Decided)

20. [General Agreement on Tariffs and Trade 1991] Agreement on Trade-Related Aspects on Intellectual Property

Rights , Including Trade in Counterfeit Goods (Annex III) Section 5: Patents.

21. [ The League for Programming Freedom 1991] Against Software Patents. ( http://www.lpf.org/)

22. [ The League for Programming Freedom 1994] Multimedia and Software Patents. (http://www.lpf.org/)

23. [ Rheingold, H 1994] The Virtual Community. Finding Connection in a Computerised World. Secker \& Warburg, London.

Acknowledgements

I would like to thank Barry Fenn, Auckland University HyperMedia Unit, for his helpful discussions. 